\title{
La crisis raigal del ser moderno colonial en plena época de la CoviD-19
}

\section{The root crisis of the modern colonial being at the height of COVID-19}

Jaime Ríos Burga

\section{Resumen}

El presente artículo aborda la crisis raigal del ser moderno colonial en plena época de la CoviD-19. Busca comprender algunas de sus causas históricas estructurales presentes en la herencia del patriarcalismo, el capitalismo y la colonialidad imperial, patrón de ser, saber y poder que ha llevado a un desencuentro total entre naturaleza-humanos, humanos-humanos, humanos-tecnologías, y conduce a la autodestrucción de la vida. Esta necrocultura nos lleva a plantear la urgente construcción política de una nueva concepción civilizatoria universal transcultural de vida del ser, saber y poder donde la libertad, la igualdad, la solidaridad, la felicidad y las diferencias en sus diversidades unan lo que la modernidad/colonialidad separó: lo verdadero con lo bueno y lo bello.

Palabras clave: ser, modernidad, colonialidad, crisis raigal, transculturalidad, vida

\begin{abstract}
This essay addresses the root crisis of the modern colonial being in full COVID-19. It seeks to understand some of its structural historical causes present in the heritage of patriarchy, capitalism and imperial coloniality. Pattern of being, knowing and power that has led to a total mismatch between: naturalism-human, human-human, human-technology nature leading to the self-destruction of life. Necroculture that leads us to propose the urgent political construction of a new cross-cultural universal civilizational conception of life of being, knowing and power where freedom, equality, solidarity, happiness and differences in their diversity unite what modernity / coloniality separated: the true with the good and the beautiful.
\end{abstract}

Key words: being, modernity, coloniality, root crisis, transculturality, life

\footnotetext{
- Docente principal de la Escuela de Sociología, Facultad de Ciencias Sociales de la Universidad Nacional Mayor de San Marcos. Actualmente es presidente de la Asociación Latinoamericana de Sociología (20192021). Orcid: 0000-0001-5950-6688 / jriosb@unmsm.edu.pe

Fecha de recepción: 4 de junio de 2020. Fecha de aceptación: 3 de agosto de 2020.
} 
Introducción

La crisis de horizonte de sentido histórico de la modernidad/colonialidad occidental pone hoy en cuestión todos los ámbitos y dimensiones de la vida. Entre el hedonismo y la soledad, y hoy cada vez más el mayor control, vemos cómo el cambio tecnocientífico redefine la relación humanos-naturaleza, humanos-humanos, humanos-tecnociencia, en sus sentidos del ser, saber y poder. Vemos cómo en la complejidad del cambio la colonialidad, el capitalismo y el patriarcalismo, como patrón de poder global en sus modelos y lógica del Estado nación, familia burguesa, empresa y racionalidad eurocéntrica (Quijano, 2000), ubican en su continuidad histórica nuevas situaciones y problemáticas, elementos de racionalidad de un sistema histórico que nos llevan a comprobar que el viejo episteme de la causalidad única de la modernidad/colonialidad ya no nos permite comprender y explicar los presentes cambios y resulta urgente construir un nuevo paradigma epistémico y teórico de vida y conocimiento inter, multi y transdisiciplinario (Preciado, 2010).

Ninguna teoría específica, por más profunda y rigurosa que sea, puede dar cuenta de estas nuevas situaciones y problemáticas de la presente transición histórica, pues estas en su complejidad contienen procesos diversos por la desintegración de sus pasadas formas de organización social y el nacimiento de nuevos patrones, procesos y tendencias de estructuración social que ya no pueden explicarse solo desde una teoría, y menos con las pasadas categorías. Desde luego, esto no significa desechar totalmente las teorías y categorías existentes, sino repensarlas e integrarlas a otras nuevas para comprender las nuevas situaciones y problemáticas desde sus propios actores y actoras, superando ese universal abstracto que oculta la plurietnicidad y multiplicidad de las identidades presentes (Chaparro, 2018) 
o las modernidades múltiples o modernidades alternativas existentes (Rueda, 2018).

La COVID-19 acelera y transforma las relaciones sociales en todas sus dimensiones y ámbitos de vida en el planeta. Como Boaventura de Sousa Santos, con razón, destaca en su último libro, La cruel pedagogía del virus (2020), el capitalismo y el neoliberalismo financiero nos han llevado en estas tres últimas décadas a una crisis permanente. El virus acelera la crisis estructural del capitalismo como sistema histórico y muestra al capital financiero como una bendición de Dios para los poderosos y una maldición para las mayorías, dinámica real donde el capitalismo, el patriarcado y el colonialismo profundizan cada vez más el sufrimiento humano, el hambre, la explotación, la discriminación racial y sexual, la sobreexplotación de las trabajadoras y los trabajadores, la muerte de los discapacitados y los ancianos.

\section{La crisis raigal}

Esta crisis raigal contiene varias crisis en permanente profundización. Como también anota Boaventura de Sousa Santos, la sociedad contemporánea percibe los riesgos que corre, va tomando conciencia de que las pandemias matan indiscriminadamente, pero no como las guerras, sequías, migraciones, etc., y el modelo social del capitalismo en su versión neoliberal muestra su inviabilidad de futuro profundizando sus irracionalidades en su radicalización como extrema derecha y derecha hiperneoliberal que profundiza bajo nuevas formas el colonialismo y el patriarcado, y, contradictoriamente, el regreso del Estado y la comunidad (De Sousa Santos, 2020).

En esta crisis la teoría de la colonialidad del poder planteada por Aníbal Quijano cobra importancia central, porque nos permite explicar y comprender la presente crisis civilizatoria en sus relaciones de dominación, explotación y 
conflicto, y sus ámbitos de autoridad colectiva, trabajo, sexo y género, naturaleza y subjetividad (Quijano, 2014). Para Rita Segato, en nuestra rica tradición teórica latinoamericana y caribeña juntamente con los aportes de la teología de la liberación, la pedagogía del oprimido y la teoría de la marginalidad, estos conocimientos son un buen punto de partida para plantearnos nuevas preguntas (Segato, 2017). Son saberes que en nuestras sociedades nos permiten desencubrir no solo la dominación sino sacar a luz la crisis raigal del sistema (Quijano, 2000; Dusell, 2007; Mignolo, 2011) y enriquecer las teorías integradas bajo una visión múltiple y multidimensional en todas sus individuaciones, sociabilidades, socializaciones, identidades y mundos simbólicos.

La historia nos enseña que el ser humano es uno y diverso desde sus orígenes. La particular construcción del yo occidental desde los griegos y el mundo "moderno" como civilitas, que invisibiliza al otro en sus propios espacios calificándolo de bárbaro y luego, en el mundo colonial americano, como indígena (Bartra, 2011). Un Yo que en sus diversidades se transforma transculturalmente hoy mostrando sus propios límites epistémicos para comprender la realidad del mundo de la vida. Como destaca César Germaná, se hace aquí imprescindible construir una epistemología otra que vaya más allá de la simplificación causal, el dualismo entre el sujeto y el objeto que anula la perspectiva intersubjetiva de conocimiento, la supuesta neutralidad valorativa en el análisis social, y asuma un carácter crítico y comprometido con la vida, la verdad, la ética y lo bello (Germaná, 2014).

Las sociedades occidentales viven varias crisis estructurales, entre ellas las crisis de individuación, sociabilidad e imaginarios agudizadas por el efecto desbastador de la Covid-19, crisis que saca a luz la profunda crisis del ser, el saber y el poder de la modernidad/colonialidad como sistema histórico. El profesor Alain Touraine señala, por ejemplo: 
No existe un movimiento populista, lo que hay es un derrumbe de lo que, en la sociedad industrial, creaba un sentido: el movimiento obrero. Es decir, hoy no hay ni actores sociales, ni políticos, ni mundiales ni nacionales ni de clase. Por eso, lo que ocurre es todo lo contrario de una guerra, con una máquina biológica de un lado y, del otro, personas y grupos sin ideas, sin dirección, sin programa, sin estrategia, sin lenguaje. Es el silencio (Touraine, 2020).

Por su parte, Noam Chomsky advertía:

Por primera vez en la historia de la especie humana, hemos desarrollado claramente la capacidad de destruirnos a nosotros mismos. Esto ha sido así desde 1945.Ahora, finalmente, se reconoce que hay procesos a largo plazo como la destrucción ambiental que lleva en la misma dirección (Chomsky, 2013).

En plena crisis originada por la Covid-19, hay que destacar:

Un día, el presidente de Estados Unidos, Donald Trump, dice:"no hay crisis, es como la gripe". Al día siguiente, dice:"es una crisis terrible y lo supe todo el tiempo". Otro día señala:"tenemos que volver al negocio, porque tengo que ganar las elecciones" (Chomsky, 2020).

Se trata de un mundo donde la racionalidad social profundiza su irracionalidad de competencia evolutiva como horizonte de sentido histórico de vida, situación que lleva día a día no solo al desencantamiento de un mercado de endeudamientos, sino también al egoísmo autodestructivo cada vez más generalizado que profundiza en los individuos y las colectividades contradictoriamente la soledad y el hedonismo en un sonambulismo generalizado del mundo occidental. Como destaca Edgar Morin al referirse impacto de la CoviD-19: 
El virus está trayendo una nueva crisis planetaria (...) Cada Estado cierra su nación sobre sí misma; la oNU no propone una gran alianza planetaria de todos los Estados. ¿Debemos pagar, en víctimas adicionales, por el sonambulismo generalizado y la falta de espíritu que separa lo que está conectado? Y sin embargo, el virus nos revela lo que estaba oculto en las mentes compartimentadas que se formaron en nuestros sistemas educativos, mentes que eran dominantes entre las élites tecno-económicas-financieras: la complejidad de nuestro mundo humano en la interdependencia e intersolidaridad de la salud, lo económico, lo social y todo lo humano y planetario. Esta interdependencia se manifiesta en innumerables interacciones y retroalimentaciones entre los diversos componentes de las sociedades y los individuos. Así, pues, la perturbación económica causada por la epidemia fomenta su propagación (Morin, 2020).

Es una lógica de racionalidad civilizatoria donde los capitalismos muestran sus efectos privatistas de intereses sin lograr articular consensos universales de vida. Como señala Morín:

El virus nos dice entonces que esta interdependencia debe dar lugar a la solidaridad humana en la conciencia de nuestro destino común. El virus también nos revela lo que he llamado la "ecología de la acción": la acción no obedece necesariamente a la intención, puede ser desviada, desviada de su intención e incluso volver como un bumerán para golpear al que la ha desencadenado. Esto es lo que el profesor Eric Caumes de la Pitié-Salpêtrière predice: Al final, son las reacciones políticas a este virus emergente las que conducirán a una crisis económica mundial (...) con un beneficio ecológico. La última paradoja de la complejidad: el mal económico podría generar una mejora ecológica. ¿A qué costo? En cualquier caso, mientras nos hace mucho daño, el coronavirus nos dice verdades esenciales (Morin, 2020).

Slavoj Zizek, desde un discurso opuesto plantea que: 
el dilema es barbarie o un comunismo reinventado (...) No soy utópico, no apelo a la solidaridad entre los pueblos. Al contrario, creo que la actual crisis demuestra que la solidaridad y la cooperación responden al instinto de supervivencia de cada uno de nosotros, y que es la única respuesta racional y egoísta que existe. No solo para el coronavirus (...) Como ha dicho Owen Jones, la crisis del clima mata a más gente que el coronavirus, sin que sintamos pánico por ello (Zizek, 2020).

Por su parte, desde otra mirada, principalmente del impacto de las nuevas tecnologías de la información y la comunicación en la vida individual, Byung Chul Han considera:

El virus no vencerá al capitalismo. La revolución viral no llegará a producirse. Ningún virus es capaz de hacer la revolución. El virus nos aísla e individualiza. No genera ningún sentimiento colectivo fuerte de algún modo, cada uno se preocupa solo de su propia supervivencia. La solidaridad consistente en guardar distancias mutuas no es una solidaridad que permita soñar con una sociedad distinta, más pacífica, más justa. No podemos dejar la revolución en manos del virus (Chul Han, 2020).

Por tanto, como en toda transición histórica de un sistema histórico a otro, vemos cómo se intensifica la concentración y la centralidad del poder del nuevo capitalismo cognitivo, la crisis de las viejas formas de organización monopólica financiera y las crisis de los Estados nación dependientes que redefinen su total sometimiento a las nuevas estructuras de poder. Con razón autores como Bringel (2020) señalan que debemos prestar atención a la dinámica del poder y sus resistencias en sus condicionantes y representaciones geopolíticas del actual caos global, la fragilidad política de los bloques regionales, la centralidad del Estado y las iniciativas locales comunitarias y territoriales. Asimismo, en una visión prospectiva de larga duración, Foster nos llama a encontrar las causas de la Covid-19 en la propia matriz del sistema capitalista: 
El propio capitalismo es el principal vector de enfermedad. Wallace ha explicado que el origen de la COVID-19 y de otros virus recientes ha sido la penetración más intensiva de la agroindustria en los sistemas naturales, lo que ha creado fisuras en los ecosistemas y entre las especies, provocando el surgimiento de pandemias mundiales. En Notes on a Novel Coronavirus, Wallace sostiene que la solución estructural es la construcción de "un ecosocialismo que mitigue la brecha metabólica entre la ecología y la economía, entre lo urbano, lo rural y lo silvestre. Evitando de esta manera que surjan peores patógenos de este tipo" (Foster, 2020).

Si tomamos estas reflexiones solo como referencia para el análisis de las diferentes crisis estructurales que vive hoy el sistema mundo moderno colonial notamos que unos llaman a tomar conciencia y evaluar el impacto civilizatorio que trae el capitalismo occidental como sistema histórico (De Sousa Santos, Touraine, Chomsky, Morin, Zizek), mientras otros llaman a comprender y explicar sus nuevos procesos (Han, Foster) o políticas de integración bajo las formas clásicas de la democracia o una democracia radical y directa como autogobierno en el cambio global (Kothari, 2020, Bizberg, 2020, Domingues, 2020).

La crisis raigal nos muestra la complejidad de su estructuración en el cambio social global que contiene varias crisis simultáneas en espacios y tiempos de larga, media y corta duración: crisis objetivas y subjetivas, intersubjetivas y simbólicas que en su composición, naturaleza, extensión, frecuencia y evolución contienen impactos cada vez más globales, de nuevo tipo, generales, atípicos y de decadencia; crisis multidimensional que encuentra su origen y desarrollo en la propia génesis del capitalismo como sistema histórico, por su relación autodestructiva con la naturaleza, los agrupamientos humanos, las tecnologías de producción y gestión.

\section{4}


La crisis raigal acelera el desencuentro naturalezahumanos estrechamente vinculado con las relaciones sociales capitalistas entre naturaleza y sociedad ya señaladas por Marx en su tiempo. Foster (2020), al referirse al impacto del Covid-19 sus causas y consecuencias señala que:

La teoría de la ruptura metabólica de Marx ya veía las relaciones ecológicas en sus complejas relaciones interdependientes de la naturaleza y la sociedad, desde un enfoque sistémico mucho antes que se desarrollará la moderna ecología sobre bases similares. Asimismo, basándose en el trabajo del químico alemán Justus von Liebig, se centró en la ruptura del metabolismo del suelo. El transporte de alimentos a cientos e incluso miles de kilómetros del campo - a la ciudad — provocó la pérdida de nutrientes esenciales del suelo, como el nitrógeno, el fósforo y el potasio. La investigación de Liebig demostró que los nutrientes no se devolvieron al suelo, sino que terminaron contaminando las ciudades. Proceso que se intensificó con la producción y acumulación capitalista generando rupturas en el intercambio de los seres humanos con la naturaleza, que Marx llamó "el metabolismo universal de la naturaleza" (Foster, 2020).

Este proceso también ya se veía afectado por el impacto del cambio tecnológico permanente del capitalismo, como Marx lo señalaba en sus Grundrisse:

Lo que se abarata es la máquina individual y sus partes componentes, pero también se desarrolla un sistema de maquinaria; la herramienta no es simplemente reemplazada por una sola máquina, sino por todo un sistema (...) A pesar del abaratamiento de los elementos individuales, el precio de todo el conjunto agregado aumenta enormemente (Roberts, 2016).

La crisis sistémica de sobreexplotación naturaleza-humanos hoy se generaliza en el planeta; Antonio Gramsci lo define estructuralmente en los siguientes términos: 
Si la clase dominante ha perdido el consenso, entonces no es más "dirigente", sino únicamente dominante, detentadora de la pura fuerza coercitiva, lo que significa que las clases dominantes se han separado de las ideologías tradicionales, no creen más en lo que creían antes. La crisis consiste justamente en que lo viejo muere y lo nuevo no puede nacer, $y$ en este terreno se verifican los fenómenos morbosos más diversos (Gramsci, 2018).

Estos conocimientos hoy son dejados de lado, o se abstraen, y para comprenderlos teóricamente se recurre a modelos sistémicos de complejidad cerrados o abiertos, esquemas relacionales que, en su selectividad y riesgos, suponen captar los procesos de supervivencia en su evolución y la capacidad reflexiva de conocerlos y afrontarlos en la casualidad y el azar de sus circunstancias (Villacañas, 2013). Así, por ejemplo, para Niklas Luhmann, "el concepto de crisis, frecuentemente usado, es también inadecuado, pues sugiere la urgencia de cambios estructurales profundos, y esto no se puede justificar únicamente por el déficit obvio de la racionalidad" (Luhmann, 1998).

No es casual que la covid-19 exprese hoy intracivilizatorialmente todos estos procesos de cambio en una ruptura en las relaciones entre la naturaleza y la vida humana, tanto como producto de las propias racionalidades y prácticas tecnoburocráticas instrumentales de poder, como las nuevas formas de organización de vida. El modelo de desarrollo global privatista muestra no solo su carácter, sino también los límites para resolver los problemas acuciantes de los millones de seres humanos que exigen una mejor calidad de vida ante el efecto devastador de la relación humanos-naturaleza profundizados por la Covid-19. Como señala Foster:

Un argumento central es que en la medida en que la economía mundial sigue creciendo, los procesos económicos humanos comienzan a rivalizar con los ciclos ecológicos del planeta, abriendo como nunca antes

\section{6}


la posibilidad de un desastre ecológico planetario. Esto ha empeorado dramáticamente por la producción de desechos y sintéticos (tóxicos). En el fondo está la lógica de la acumulación del capital, porque esta constituye la realidad estructural del capitalismo monopolista. La colisión entre el capitalismo y el medio ambiente no significa otra cosa que una catástrofe en el siglo XXI, a menos que la humanidad cambie repentinamente de rumbo (Foster, 2020).

Se trata de una crisis permanente donde la racionalidad instrumental hegemónica y los dogmatismos relativistas o nihilistas niegan o esconden las diversas crisis (crisis climática, crisis de soledad, patriarcalismo, nuevas desigualdades y exclusiones, crisis financieras, etcétera) e imponen nuevos mecanismos de control y dominación global. Como anota Boaventura de Sousa Santos, detrás de la idea de una crisis permanente están no solo los recortes en salud, educación, bienestar social o el deterioro de las condiciones salariales, sino también la nuevas concentración y centralidad del capital, pues:

El objetivo de la crisis permanente es que esta no se resuelva. Ahora bien, ¿cuál es el objetivo de este objetivo? Básicamente, hay dos objetivos: legitimar la escandalosa concentración de riqueza e impedir que se tomen medidas eficaces para evitar la inminente catástrofe ecológica. Así hemos vivido durante los últimos cuarenta años. Por esta razón, la pandemia solo está empeorando una situación de crisis a la que la población mundial ha estado sometida. De ahí su peligrosidad específica. En muchos países, los servicios de salud pública estaban hace diez o veinte años mejor preparados para hacer frente a la pandemia que en la actualidad (De Sousa Santos, 2020).

Vemos descarnadamente aquí cómo, para el poder hegemónico en su vertiente racista, la vida social solo es una mercancía desechable. Entre el hedonismo y la soledad, los individuos y las colectividades, en pleno impacto de la 
Covid-19, se preguntan: ¿Esto es vida? ¿Tiene sentido vivir así en un mercado que día a día devora la naturaleza, los cuerpos y las emociones? ¿Cómo vivir en un mundo en el que unos pocos se enriquecen mientras millones de seres humanos viven y migran bajo diferentes formas de violencias? ¿Qué futuro le espera a mi familia, mis hijos, mi territorio, mi país?

La sociedad occidental incuba una profunda crisis estructural del ser individual y colectivo, crisis que, por el impacto del modelo neoliberal, no solo ha destruido el "Estado de bienestar" en sus necesidades básicas (alimentación, salud, vivienda, educación, ocio, etcétera) sino también en el encuentro del yo y el otro como un nosotros de vida. No es casual que en Inglaterra se cree el Ministerio de la Soledad para afrontar los costos sociales ante el creciente descontento social existente. La CovID-19 profundiza esta situación con la mayor muerte de las personas de la tercera edad en Bélgica (Pleyers, 2020), y también con las migraciones se muestran las nuevas asimetrías sociales de la nueva exclusión global multirraciales. Actores principalmente jóvenes plantean mayores demandas de democratización en una dinámica urbana cada vez más cosmopolita consumista, pero donde, como también destaca Geoffrey Pleyers, los pueblos, clases sociales y grupos étnicos van más allá de los propios movimientos sociales (Pleyers, 2018).

Las luchas sociales diversas irrumpen en el mundo cuestionando el modelo privatista neoliberal, como lo observamos en Francia y Chile, por ejemplo. Los "chalecos amarillos" reaccionan ante el impacto de la financiarización buscando desesperadamente dar solución a sus problemas acuciantes: agua, luz, alimentación, etc. Jacqueline Mouraud, una de sus líderes fundacionales, dice: "Ya no sé qué se necesita para salir de esta crisis (...) Emmanuel Macron nos habla del fin del mundo, pero nosotros no llegamos a fin de mes". Otros testimonios destacan: "luchamos para que 
no se eleve el costo de vida, los impuestos; buscamos una educación y salud pública de calidad" (Rosas, 2018). Estos movimientos llevan al poder a recurrir a la razón de Estado como único medio de control de poder. Vemos, así, cómo en Francia se desplegaron más de 89,000, y solo en París más de 8,000 (Garita, 2018).

Las movilizaciones en Chile, incluso en plena pandemia, muestran el agotamiento del modelo neoliberal. La elevación del costo de vida lleva a "evasiones masivas", el saqueo de los supermercados, los ataques a las instalaciones públicas, los paros en puertos y cortes de carreteras. En respuesta, el estado de emergencia y el toque de queda, a tal punto, que en su desesperación el presidente Piñera, en su mensaje del domingo 20 de octubre de 2019, señaló:

Estamos en guerra contra un enemigo poderoso e implacable que no respeta nada ni a nadie y que está dispuesto a usar la violencia sin ningún límite, incluso cuando significa la pérdida de vidas humanas, con el único propósito de producir el mayor daño posible.

La COVID-19 paraliza estas movilizaciones diversas, pero ellas seguirán cada vez más organizadamente en el mundo.

\section{Una crisis de horizonte de sentido histórico}

La COVID-19 radicaliza la crisis estructural de horizonte de sentido de la modernidad/colonialidad en todas sus dimensiones y aspectos de la vida. Centraliza el biopoder, pero también gesta nuevas formas de organización de un nuevo poder al servicio de la vida. Es una etapa de transición de la crisis civilizatoria global y de la crisis del mundo occidental en la que se desestructuran todas las viejas relaciones sociales, nacen y desarrollan nuevos procesos de estructuración bajo diferentes modelos sociopolíticos, y se redefine el contenido de los Estados naciones hegemó- 
nicos/contrahegemónicos, y el nuevo papel crucial de los modelos de desarrollo con sus impactos diferenciados en la vida social, los cuerpos y los sentidos del ser, saber y poder en el mundo.

Se trata de una etapa de reproducción social que, en su conjunto, integran actores y actoras sociales bajo nuevos procesos de acumulación y realización del capital cognitivo y financiero corporativo, por un lado, y por otro el nuevo papel del Estado nación global. Estructuraciones y destructuraciones sociales que impactan en los ecosistemas y sus recursos en una crisis de "colapsología" del sistema histórico moderno/colonial occidental llevan a pensar en nuevos modelos de desarrollo sostenibles. Como anota Bruno Latour:

La crisis sanitaria está insertada (...) en una mutación ecológica irreversible. Si bien tenemos muchas posibilidades de superar la primera, no tenemos ninguna de sobrepasar la segunda (...) La primera lección del coronavirus es la más increíble, $y$ es que es posible en unas pocas semanas suspender en todo el mundo y simultáneamente un sistema económico que nos decían que era imposible ralentizar o redirigir (...) Por lo tanto, estima que "sería una pena no utilizar la crisis sanitaria para descubrir otros medios de entrar en la mutación ecológica de otra manera que no sea a ciegas" (Latour, 2020).

Vemos cómo, aquí, los sistemas se autorreproducen hasta transformarse en otros sistemas. Unos grupos de poder se resisten a cambiar profundizando sus propias racionalidades, mientras otros agrupamientos dan origen, o desarrollan, a nuevas formas de organización de poder en ecosistemas diferenciados. Igualmente, a escala social vemos surgir nuevas individuaciones, sociabilidades, socializaciones e identidades, imaginarios y mundos simbólicos en red de redes. Actores y actoras diversos que, ante la privatización general de la vida social, reivindican lo público y 
comunitario ante la creciente corrupción del sistema y las nuevas expectativas individuales y colectivas de consumo e integración geoeconómica, política, social y cultural de los pueblos del mundo.

El poder hegemónico y el contrahegemónico se enfrentan en una nueva guerra fría. Estados Unidos acelera su crisis polarizando su conflicto con China y Rusia, bajo el imaginario del sueño americano en crisis del Estado nación, integrando a todas las fuerzas posibles a su favor. Es una crisis de transición de un mundo unipolar a otro multipolar. La COVID-19 muestra cómo en Estados Unidos su sistema se basa en una profunda desigualdad social y racial con altas tasas de mortalidad de las comunidades afro e hispano latinoamericano y caribeño en sus territorios, lo que muestra una desestructuración y una nueva estructuración de los grupos étnicos, culturales, etarios, políticos, religiosos, sexuales, de género, nacionales, transnacionales, etc. Son actores y actoras diversos que redefinen sus sentidos del ser individual y colectivo inter e intra generacionales en sus identidades y culturas cada vez más sujetas a la globalización.

Se trata de una nueva dinámica transcultural donde lo inter, multicultural y transcultural se generaliza en procesos diversos de integraciones, resistencias, aculturamientos, sincretismos y nuevos procesos étnico-raciales y socioeconómicos, políticos y culturales, espacios y territorios donde confluyen y coexisten actoras y actores que se integran en la unidad de sus diferencias; aunque también coexisten viejos y nuevos fundamentalismos religiosos, luchas relacionadas con autonomías que muestran diversos grados de interdependencia, o descontentos contra nuevas dependencias globales. Son dinámicas transculturales que hoy la covid-19 aísla, llenando sus vacíos existenciales cada vez más con los deseos de una relación con el afuera (Badiou, 2018). 
Vemos cómo la "concepción del desarrollo" lineal evolutivo, con su teoría sustantiva de "orden y progreso" occidental, entra en una crisis terminal. Como destaca el maestro Pablo Gonzales Casanova: "con el colonialismo y el darwinismo mitologizado [que] le asignaron al hombre blanco, en especial al anglosajón, la condición de una especie superior cuyo destino y 'carga' es dominar al mundo" (Gonzales, 2004). El imaginario civilizatorio hegemonista y racista destruye todo diálogo inter y transcultural democrático y busca volver imponer el viejo discurso del Estado nación homogeneizador nacionalista. Es un discurso opuesto al imaginario nacionalista, que busca un encuentro con el otro integrando los imaginarios nacionales transculturalmente en encuentros y en resistencias lingüísticas (Cuestas, 2018), o un mundo social nacional que comparta su palabra con el otro interculturalmente (Márquez, 2018).

La COVID-19 remece las estructuras y los procesos de individuación y sociabilidad en sus mundos cotidianos. La feroz competencia individualista que despersonaliza el ser y los propios anhelos individuales y colectivos de vida en sus propios cuerpos y emociones empieza a ponerse en cuestión. Los jóvenes sienten que su vida ya no les pertenece, sino en la intensidad del trabajo o la supervivencia, cotidiana son partes de una economía y sociedad que no les da vida. Se sienten que son parte de un mecanismo que no les da felicidad sino los agota en su hedonismo y soledad que mata. De ahí que reaccionen bajo diferentes formas entre el placer momentáneo y la droga como desfogue, un nuevo anarquismo o una actitud reflexiva de vida anhelando salir de esta "jaula de hierro".

Las personas se van dando cuenta de que el individualismo ciudadano patriarcal impuesto por la secularización occidental de lo divino, la modernidad del mercado y la política del Estado nación, incluso en su versión más liberal, ya no le da sentido a su vida, son solo promesas que han 
quedado en el discurso y no resuelven sus problemas vitales. Son procesos de individuación y sociabilidad donde las ideas vitales de Nietzsche quedan cortas para comprenderlas, pues ya no solo Dios ha muerto, sino también el sentido de vida es controlado y manipulado destructivamente por el biopoder, que hace creer que las personas son libres pero, en su adicción al consumo, son atrapadas por la voracidad de la financiarización, la neurociencia y la comunicación simbólica de dominación mental. Es una soledad que no libera sino destruye toda libertad individual y colectiva.

En esta dinámica inter e intracivilizatoria global los individuos no occidentales desean vivir como los occidentales, pero sin lograr muchas veces integrarse a la cultura occidental dominante, porque viven en su imaginación bajo nuevas formas de sociabilidad y racismos "el que vive por lo mismo perecerá por lo mismo" (Baudrillard, 1991). Crisis personales e interpersonales e intergeneracionales se viven dentro y fuera del propio sistema en nuevas individuaciones entre lo real y lo virtual. Como destaca Marcelo Arnold:

La generalización de los vínculos marcadamente instrumentales que caracterizan a las organizaciones en marcha de la mano con la evolución social. Sus diversas estructuras emergen cuando se ajustan los medios para la búsqueda o cumplimiento de fines; de tal modo, sus cálculos racionales han desplazado y entrado en conflicto con las relaciones sociales, aparentemente desinteresadas, basadas en valores o por la tradición (Arnold, 20I4).

Use trata de una contradicción del yo y el otro en sí misma que el sistema ya no puede resolver en un nuevo encantamiento del mundo. Como bien destaca Byung-Chul Han, el poder hegemónico, en su dinámica de control, generaliza la individuación en egos que se autoexplotan en una competencia perversa que desarma crecientemente el yo, una sociedad del rendimiento donde la socialización y la 
sociabilidad van más allá de la sociedad disciplinaria de Foucault, manipulando las emociones y fragmentando lo colectivo. Es un yo individual donde el ser no se siente ya dueño de sí mismo, sino verdugo, víctima y sujeto de obediencia del sistema. En este biopoder la neurociencia, la psicocomunicación, la sociología, la ciencia política, la cultura y el marketing, crean una hiperatención que agota la vida entre el hedonismo y el misticismo, y se explota en una individuación que se naturaliza bajo la idea de un individuo individualizado "libre" (Han, 2017).

Las crisis del ser, en sus mundos de trabajo, géneros, cuerpos y emociones, conducen a las mayorías a los nuevos desclasamientos, exclusiones e integraciones individuales y colectivos, todo en un mundo social cada vez más violento, como muestra la experiencia chilena (Pavez y Kraushaar, 2011), o un mundo como pensaba Sloterdijk, donde las relaciones abrazadoras de abrigo de la tradición, la participación y la comunión caen cotidianamente en la manipulación técnica, condenados a "ser-en", un mundo social cada vez más tóxico donde los intereses individualistas se cierran en el círculo de la desconfianza de su propia racionalidad (Sloterdijk, 2003).

Una sociedad al decir de Lipovetsky de la decepción de no-ser-del-todo, en una insatisfacción permanente que entre el sobrevivir o el vivir y saber venderse o inventarse en su gran mayoría viven un profundo vacío en situaciones crecientes de depresión, suicidios, adicciones y momentos paradójicos de "felicidad" histerizadas por el hiperconsumo (Lipovetsky, 2008). Campos diversos de actuaciones donde, sin duda, al decir de Bourdieu, los más desposeídos pierden la lucha simbólica por ser reconocidos o ser aceptados como parte de la humanidad (Bourdieu, 2006)

Por otra parte, como anota también Bauman, la propia racionalidad del poder no permite otra opción cultural alternativa, pues su objetivo no es satisfacer socialmente 
las necesidades, los deseos y los apetitos del conjunto de los pueblos o clases sociales no dominantes, sino convertir y reconvertirlos en consumidores, clientes, productos; es decir, elevar el estatus de los consumidores al de bienes de cambio vendibles (Bauman, 2007), una vida líquida de individualización y sociabilidad no lineal en sistemas complejos abiertos que imponen sus reglas entre la incertidumbre, el riesgo y la innovación (Beck, 2002)

En esta vida la racionalidad instrumental lleva a una pérdida de todo sentido ético del ser, y en la cual su egoísmo conduce permanentemente al cansancio, la separación, el aislamiento y la división de los seres humanos. Esta concepción civilizatoria de la modernidad/colonialidad se generaliza y crea una movilidad individual e institucional en una competencia destructiva, en alianzas de intereses cambiantes y contradictorios, en procesos de repatriarcalización, racialización y patrimonialismo del ser en el cambio global (Martins, 2018), pero también de visibilización de los movimientos sociales con enfoque de género.

Por su propia reproducción, este patrón de poder crea y renueva sus mecanismos subjetivos e intersubjetvos de control económico, social, político y cultural, ya no principalmente desde la coerción, sino desde una política inteligente que agrega la subjetividad individual y colectiva como un todo (Han, 2014), frente a lo cual la covid-19 hace un alto que acentúa el control ejercido por parte del Estado nación. Pero como también destaca Chul Han, se hace cada vez más evidente un control simbólico de la vida y las mentes que sistémicamente son bombardeadas por los lenguajes simples de lenguajes manipulatorios que penetran en los cuerpos, las subjetividades y las emociones y los naturalizan como "clientes" y no como "personas" y coexisten, paradójicamente, con otras formas socioculturales y simbólicas individuales y colectivas que anhelan construir un nuevo horizonte de sentido histórico de una civilización de vida. 
La construcción de nuevos horizontes de sentidos de vida Actualmente vemos surgir nuevos imaginarios civilizatorios sobre la base de la revolución de la información y la comunicación. Estos imaginarios hoy no solo buscan cumplir con las promesas y los ideales de la modernidad: libertad, igualdad, fraternidad y felicidad, sino también pretenden integrar la revolución científico-tecnológica a las diferentes formas de individuación, sociabilidad, socialización y mundos simbólicos de la vida. Se trata de un proceso en el cual los nuevos actores y actoras buscan nuevas racionalidades de la vida social, como destaca Byung-Chul Han al referirse al impacto de la nueva revolución 5G, o al manejo del Big Data. Estos cambios, a la vez que liberan las individuaciones y las sociabilidades, profundizan el control del neuropoder, a través de lo cual se suprimen libertades y se crean nuevas desigualdades y exclusiones sociales, en el marco de una creciente privatización del conocimiento, del control de la psique y del conocimiento en el nivel prerreflexivo individual y colectivo (Han, 2014).

El ser colonial sufre aquí, también, profundos cambios en sus especificidades. En la glocalización (global + local) el cambio fluctúa entre una individuación y sociabilidad de imitación, creatividad, o ambas, bajo la lógica hegemónica mediática, y otras formas de resistencia o cambio sociopolítico y cultural. Pero sus procesos de estructuración del yo van más allá de la simple dependencia acorde con sus movilidades sociales e institucionales diferenciadas entre lo formal, lo informal y lo ilegal de sus economías, culturas, clases, naciones y dinámicas transnacionales (Duran, 2007). Las nuevas clases medias y populares urbanas en nuestros países son casos sobresalientes, porque se integran diferenciadamente y entran en conflicto con la propia financiarización hegemónica.

La CEPAL, al referirse al impacto del COVID-19, destaca con razón que: 
La pandemia de la enfermedad por coronavirus (COVID-19) ha puesto de relieve, de forma inédita, la importancia de los cuidados para la sostenibilidad de la vida y la poca visibilidad que tiene este sector en las economías de la región, en las que se sigue considerando una externalidad y no un componente fundamental para el desarrollo. La crisis sanitara en curso pone en evidencia la injusta organización social de los cuidados en América Latina y el Caribe. Urge pensar las respuestas a las necesidades de cuidados desde un enfoque de género, ya que, como ha demostrado la Comisión Económica para América Latina y el Caribe (CEPAL) en reiteradas ocasiones, son las mujeres quienes, de forma remunerada o no remunerada, realizan la mayor cantidad de tareas de cuidados (CEPAL, 2020).

En este escenario de pandemia, América Latina y el Caribe aceleran la nueva asimetría estructural de diferenciación en sus sociedades. Como destaca Pablo Vommaro, refiriéndose al impacto multidimensional de la covid-19, en los jóvenes de nuestra región se agudizan y profundizan las desigualdades inter e intrageneracionales; falta reconocer las situaciones juveniles en sus diferencias y diversidades, los obstáculos o limitaciones que enfrentan los jóvenes, o las barreras creadas por la clausura del espacio público, y los aportes que ofrece el emprendimiento social comunitario o territorial. Hace falta reconocer la movilización o la protesta social contra el profundo impacto sobre la precarización laboral en el empleo, la diferenciación educativa por su desigual conectividad, su impacto sobre los jóvenes de los sectores populares, las violencias de género y las relaciones intergeneracionales. Falta plantear una mirada interseccional que considere la brecha generacional, sus condiciones de género, sus territorios, su situación socioeconómica, de trabajo, migración, cultura y educación, y una mirada que garantice los derechos y la expresión de los sujetos (Vommaro, 2020).

La situación plantea el desafío de redefinir o construir nuevos conceptos para comprender y explicar las complejas 
situaciones que se avecinan, como la de economía de vida, derechos de la naturaleza, derechos básicos sanitarios, alimentarios, vivienda, educación, ocio, etc. De Munck señala al respecto:

La crisis actual exige un nuevo concepto:soberanía sanitaria. En el campo de la salud, sería la contrapartida directa de la "soberanía alimentaria" exigida por los movimientos de justicia global de los agricultores. De hecho, es absurdo que los europeos importen máscaras protectoras de China o dependan en gran medida de las drogas producidas en los Estados Unidos. El estado debe esforzarse por localizar la producción de equipos básicos de salud pública. El mercado mundial desregulado difunde las capacidades de producción de acuerdo con la ley de especialización, que está sujeta a una ventaja comparativa. Es por eso que ninguna comunidad puede confiar en el libre comercio para su supervivencia (De Munck, 2020).

Por tanto, gestar en la presente transición civilizatoria global la conciencia de que la profunda crisis raigal del sistema conduce al planeta y la vida humana a su autodestrucción por la racionalidad que impone la modernidad/colonialidad neoliberal sobre la naturaleza y los humanos. Espacios urbanos de mercado donde el Estado mínimo lo privatiza todo abandonando las pasadas formas del "Estado de bienestar". Como escribe Enrique Dussel:

Creemos que estamos viviendo por primera vez en la historia del cosmos, de la Humanidad, los signos del agotamiento de la Modernidad como última etapa del Antropoceno, y que permite vislumbrar una nueva Edad de Mundo, la Transmodernidad (de la que hemos expuesto algunos aspectos en otros artículos y libros). En esta, la Humanidad deberá aprender, a partir de los errores de la Modernidad, a entrar en una Nueva Edad del Mundo donde, partiendo de la experiencia de la necro-cultura de los últimos cinco siglos, debamos ante todo afirmar la Vida por sobre el capital, por sobre el colonialismo, por sobre el patriarcalismo y por sobre 
muchas otras limitaciones que destruyen las condiciones universales de la reproducción de esa Vida en la Tierra (Dussel, 2020).

Hay que desarrollar una nueva concepción civilizatoria universal de vida que afirme nuevas formas de vivir, producir, consumir y convivir en lo económico, social, político y cultural, naturalizando la vida social y humanizando la naturaleza con todos los saberes de la vida. Se necesita un cambio del ser individual y colectivo bajo políticas de vida sostenibles; señala Boaventura de Sousa Santos:

La primera es crear un nuevo sentido común, la idea simple y evidente de que, especialmente en los últimos cuarenta años, hemos vivido en cuarentena, en la cuarentena política, cultural e ideológica de un capitalismo encerrado en sí mismo, así como en la cuarentena de la discriminación racial y sexual sin las que el capitalismo no puede sobrevivir. La cuarentena causada por la pandemia es, después de todo, una cuarentena dentro de otra. Superaremos la cuarentena del capitalismo cuando seamos capaces de imaginar el planeta como nuestro hogar común y a la naturaleza como nuestra madre original a quien le debemos amor $y$ respeto. No nos pertenece. Le pertenecemos a ella. Cuando superemos esa cuarentena, seremos más libres ante las cuarentenas provocadas por la pandemia (De Sousa Santos, 2020).

Por tanto, lo que visibiliza hoy la COVID-19 es la profunda crisis del sistema mundo moderno colonial, crisis raigal de larga, mediana y corta duración que, por los efectos de la aplicación del modelo neoliberal, estalla hoy globalmente y pone en riesgo la vida en todos los planos. Desencanto que lleva a pensar en construir nuevos horizontes de sentido históricos de vida que vinculan naturaleza-humanidad, humanos-humanos, humanos-tecnociencia en organizaciones inteligentes de vida y no en paraísos pasajeros del consumo (Lipovestsky, 2007), a pesar de su ofrecida generalización. 
En síntesis, asistimos al desafío de ser, saber y poder bajo una nueva concepción civilizatoria universal de vida. Este paradigma nos afirma como naturaleza-humanos interdependientes en organizaciones sociales reflexivas, que mejoran la calidad de vida de los ecosistemas y pueden incluso re-encantar al mundo ante la crisis raigal de la racionalidad instrumental. Se necesita un mundo donde los mercados y la política, las ciencias y las tecnologías, sirvan no para el control y dominio de unos y unas contra otras y otros sino para afirmar un buen y bien vivir. El horizonte de sentido histórico, bajo políticas democráticas de vida, afirma la transmodernidad y la transculturalidad de la vida social y cumple, así, con las promesas de igualdad, libertad, solidaridad, felicidad y derecho a la diferencia, que la modernidad/colonialidad imperial occidental racialmente separó y, sin embargo, es indisociable: lo verdadero con lo bueno y lo bello al servicio de la vida.

Bibliografía

\section{0}


Bizberg, I. (2020).“Pensar más allá de la pandemia”. Madrid:El Bibliografía

País.Disponible en:https://elpais.com/elpais/2020/03/3 I/ opinion/I5856/0408_637589.html.

Bourdieu, P. (2006). Meditaciones pascalinas. Barcelona:Anagrama.

Bringel, B. (2020). "Geopolítica de la pandemia, escalas de crisis y escenarios en disputa". Geopolítica(s) Revista de Estudios sobre Espacio y Poder. Madrid: Universidad Complutense.

CEPAL (2020). La pandemia del COVID- 19 profundiza la crisis de los cuidados en América Latina y el Caribe. Disponible en: https://repositorio.cepal.org/handle/ I I 362/45335.

Cuestas, J. (2018)."Runashimi: colonialidad, poder y resistencia”. FAIA, vol. 7, núm. 3I, Ecuador.

Chaparro, A. (20I8). “Tiempos (pre/post) modernos”. En E. Rueda y S.Villavicencio (Ed.). Modernidad, colonialismo y emancipación en América Latina. Buenos Aires: CLACSO.

Chomsky, N. (2013).“Chomsky: EE.uU. está acelerando la destrucción del mundo”. Disponible en: https://actualidad. rt.com/actualidad/view/96580-chomsky-eeuu-destruccion-mundo.

(2020). "Noam Chomsky: Crisis del coviD-19 se agravó por traición de EE.Uu.”. Disponible en: https://www.hispantv.com/noticias/ee-uu-/463087/ chomsky-coronavirus-trump.

Domingues, J. (2020). Coronavirus, ciencias sociales y política. CLACSO. Disponible en: https://www.clacso.org/coronavirus-ciencias-sociales-y-politica/.

Durand, F. (2007). El Perú fracturado. Formalidad, informalidad y economía delictiva. Lima: Fondo Editorial del Congreso del Perú.

Dussel, E. (2007). Política de liberación: Historia mundial y crítica. Madrid: Editorial Trotta.

(2020). "Cuando la naturaleza jaquea a la orgullosa modernidad”. Council Hemispheric Affair. Disponible 
en: http://www.coha.org/cuando-la-naturaleza-jaquea-a-la-orgullosa-modernidad/.

Foster, B. (2020). Entrevista: "El capitalismo ha fracasado. La disyuntiva es 'la ruina o la revolución'”. Kaosenlared. Disponible en: https://kaosenlared.net/entrevista-a-bellamy-foster-el-capitalismo-ha-fracasado-la-disyuntiva-es-la-ruina-o-la-revolucion/.

Germaná, C. (20I4). Una epistemología otra. La contribución de Aníbal Quijano a la reestructuración de la sociología de América Latina. Lima: URP.

(20/8). "Un pensamiento crítico alternativo al eurocentrismo". Revista de Política y Cultura, año 3, núm. 6, Septiembre. Lima: Ojo Zurdo.

Gonzáles, P. (2004). Las nuevas ciencias y las humanidades. De la academia a la política. México:Anthropos.

Gramsci, A. (20I8). Pasado y presente cuadernos de la cárcel. Barcelona: Editorial Gedisa.

Handke, P. (2006). Ensayo sobre el cansancio. Madrid:Alianza Editorial.

Han, Byung-Chul (20I4). Psicopolítica. Barcelona: Herder. (20I7). La sociedad del cansancio. Barcelona: Herder. (2020). “El virus no puede reemplazar a la razón”. https://www.semana.com/cultura/articulo/byung-chulhan-el-virus-no-puede-reemplazar-a-la-razon/658847.

Kothari, A. (2020). "Crisis de coviD-19 y transformaciones a largo plazo: alternativas de la India”. Open Democracy. Disponible en: https:/www.opendemocracy.net/en/ openmovements/ covID-19-crisis-and-long-term-transformations-alternatives-india/.

Latour, B. (2020). "No es el fin del mundo, es una advertencia”. Chicago Tribune. Disponible en: https://www. chicagotribune.com/espanol/sns-es-no-es-fin-mundo-. Lipovetsky, G. (2007). La felicidad paradójica Ensayo sobre la sociedad de hiperconsumo. Barcelona:Anagrama. 
(2008). La sociedad de la decepción Entrevista con Bertrand Richard. Barcelona: Editorial Anagrama.

Luhmann, N. (1998). Sistemas sociales. Lineamientos para una teoría general. Barcelona:Anthropos.

Márquez, Á. (20I8). "El rol de construcción de la praxis intercultural”. FAIA, vol. 7, núm. 3I. Ecuador.

Martins, P. (2018). "Repatrialização numa sociedade sem trabalho". O Povo. Disponible en: http://mail.glogle.com/ mail/u/o/\# search/paulohenriquemar\%40gamil.co.

Mignolo, W. (20I I). The Darker Side of Western Modernity: Global Futures, Decolonial Options. USA: Durham Duke University Press.

Morin, E. (2020). "Lo que el coronavirus nos está diciendo". SERVINDI. Disponible en: https://www.servindi.org/

Munck, J. de (2020). "Tres respuestas a la crisis del coronavirus”. Open Democracy. Disponible en: https://www. opendemocracy.net/en/democraciaabierta/three-responses-coronavirus-crisis/.

Paul, F. (2019). "Protestas en Chile: 4 claves para entender la furia y el estallido social en el país sudamericano". BBC News. Disponible en: https://www.bbc.com/mundo/ noticias-america-latina-50 I I 5798.

Pleyers, G. (20I8). Movimientos sociales en el siglo Xxı. Buenos Aires: CLACSO.

Preciado, J. (20I0). "La construcción de una geopolítica crítica desde América y el Caribe. Hacia una agenda de investigación regional”. Geopolítica (S), vol. I, núm. I. Disponible en: http://revistas.ucm.es/index.php/GEOP/ article/view// 4275 .

Pleyers, G. (20I8). Movimientos sociales en el siglo Xxı. Buenos Aires: CLACSO.

(2020)."Bélgica el país con más muertos por millón de habitantes”. Madrid: El País. Disponible en: https:// elpais.com/sociedad/2020-04- I 9/belgica-el-pais-conmas-muertos-por-habitantes.html. 
Quijano,A. (2000),“Colonialidad del poder, eurocentrismo y América Latina”, en Edgardo Lander (Comp.), La colonialidad del saber: eurocentrismo y ciencias sociales, Perspectivas latinoamericanas, CLACSO, Buenos Aires.

(Ed.) (20I4a). Des/colonialidad y bien vivir. Lima: Editorial Universitaria URP.

(20|4b). "Bien vivir": entre el "desarrollo" y la descolonialidad del poder. Descolonialidad y Bien vivir. Un nuevo debate en América Latina. Lima. URP: Editorial Universitaria. Roberts, M. (2016). "La teoría marxista de las crisis económicas en el capitalismo". Sin Permiso. Disponible en: https://www.sinpermiso.info/textos/la-teoria-marxista-de-las-crisis-economicas-en-el-capitalismo

Rueda, E. (20I8). “De palimpsestos y escisiones. La modernidad en el pensamiento emancipatorio latinoamericano". En E. Rueda y S. Villavicencio (Ed.). Modernidad, colonialismo y emancipación en América Latina. Buenos Aires: CLACSO.

Segato, R. (2017). “Aníbal Quijano y la perspectiva de la colonialidad del poder en La crítica de la colonialidad en ocho ensayos y una antropología por demanda". Disponible en: http://leedor.com/20 I7/07/23/la-critica-de-la-colonialidad.

Sloterdijk, P. (2003). Temblores de aire En las fuentes del terror. Valencia: Pre-Textos.

Sousa Santos, B. de (2020a). La cruel pedagogía del virus. Buenos Aires: CLACSO.

(2020b). "Virus: todo lo sólido se desvanece en el aire”. Rebelión. Disponible en: https://rebelion.org/virustodo-lo-solido-se-desvanece-en-el-aire/.

Touraine, A. (2020). "Esta crisis va a empujar hacia arriba a los cuidadores”. El País. Disponible en:https://elpais.com/ ideas/2020-03-28/alain-touraine-esta-crisis-va-a-empujar-hacia-arriba-a-los-cuidadores.html. 
Villacañas,J.(20I3).“Crisis: ensayo de definición”. Vínculos de Bibliografía Historia, 2. Disponible en: https://ruidera.uclm.es/xmlui/ bitstream/handle/I 0578/3 I 26/Crisis,\%20ensayo\%20 de\%20definici\%C3\%B3n.pdf?sequence=I.

Vommaro, P. (2020). "Hablemos de Derechos Humanos en el contexto del covID-19". Disponible en: https://www. clacso.org/hablemos-de-derechos-humanos-en-el-contexto-del- CoviD- $19 /$.

Zizek, S. (2020). "El dilema es barbarie o un comunismo reinventado”. El Mundo. España. Disponible en: https:// www.elmundo.es/cultura/literatura/2020/03/25/.

Otras referencias:

Garita, N. (20I8). Testimonio en vivo desde París a mi correo personal. Diciembre. 